\title{
An experimental study of bipolar reduction at Zhoukoudian locality 1, North
} China

\author{
Feng Li
}

Key Laboratory of Vertebrate Evolution and Human Origins of Chinese Academy of Sciences, Institute of Vertebrate Paleontology and Paleoanthropology, Chinese Academy of Sciences, 142 Xizhimenwai Street, Beijing 100044, China

\section{Abstract}

Bipolar reduction is usually connected with quartz material, and the less predictable fracture of quartz makes the recognition of bipolar products highly uncertain. At Zhoukoudian locality 1 (ZKD1) in north China, numerous bipolar reduction artifacts were reported, and this has become a major technological label of the lithic industry. However, few experimental analyses have been conducted on this site. This study conducted experimental analysis to build an experimental referential framework for distinguishing bipolar products, and then chose a small lithic artifact sample from layers 4-5 to evaluate the role of bipolar reduction. These data show freehand reduction produces a higher percentage of usable flakes and also more cutting edges per flake than that by bipolar reduction in general. More freehand reduction flakes were chosen as tool blanks than bipolar flakes. The contribution of the bipolar flaking method to the lithic industry of Zhoukoudian locality 1 has been overestimated. This paper proposes that bipolar reduction is likely to have been an expedient strategy as a supplement of freehand reduction at Zhoukoudian locality 1. Consequently, it should be seen as an adaptive characteristic of the industry instead of an evolutionary one, and also cannot be used to trace technological diffusion or cultural tradition.

Keywords: Zhoukoudian locality 1, Quartz, freehand reduction, bipolar reduction, Experimental study

\section{Introduction}


Bipolar reduction is defined as a percussion technique in which a stone core is placed on an anvil and struck with a stone hammer on the top of the core to produce blanks (Lowe 1946; Pei and Zhang 1985; Diez-Martín et al. 2011; Gurtov and Eren 2014). Its products are found in many assemblages in a vast area from Olduvai Gorge in Africa to Choukoutien (now Zhoukoudian Locality 1) in East Asia (Leakey 1971, Pei and Zhang 1985), and also in a very long time period from the very early stages of the Paleolithic such as the Olduvai sites to the very late stage of chipped stone as in some Paleoindian sites (e.g., Binford and Quimby 1963; Diez-Martín et al. 2009). The function of bipolar products is controversial, but they are more possibly used as cores and flakes (Shott, 1989, 1999; LeBlanc, 1992; Chen 1998; Hiscock, 2015).

Bipolar reduction is frequently connected to the exploitation of inhomogeneous quartz, and the less predictable fracture of quartz makes the identification of quartz artifacts difficult relative to other types of stone. However, experimental referential frameworks have been developed recently from a series of systematic experiments (Barham 1987; Kuijt et al. 1995; Diez-Martín et al. 2011; Driscoll 2011; Gurtov and Eren 2014). These data offer an opportunity to reassess the bipolar products in some assemblages where systematic experimental analysis is absent.

Since the artificial nature of vein quartz fragments was first recognized in 1931 (Breuil 1931; Pei 1931) at ZKD1, numerous stone artifacts manufactured from vein quartz have been unearthed. This site is well known for its vein quartz industry and most importantly its human fossils. Much more research has been undertaken on the human fossils, the dating of the site and fire use analyses than on the lithic materials (Weiner et al. 1998; Shen et al. 2009; Wu et al. 2011; Zhang et al. 2014; and references therein). After the synthetic study by Pei and Zhang (1985), little research on the lithic materials has been done. In Pei and Zhang's (1985) book, the bipolar technique was thought to have been the main method applied on vein quartz to produce blanks followed by freehand percussion, especially above layer 7 .

Numerous bipolar products were thought to be a major technological characteristic of the ZKD1 stone industry. Furthermore after summarizing bipolar products in the Chinese Paleolithic, Zhang (1983) has proposed that the bipolar 
technique could be treated as a link between the Early and Late Paleolithic in China. As a consequence, the bipolar technique was given a meaning of cultural affiliation as a way of tracing technological diffusion. However, bipolar products never overwhelmingly dominated any assemblages in China except for some layers at ZKD1 (see Table 1 in Zhang 1998). The role of bipolar products at ZKD1 should be reevaluated, considering the uncertainty of distinguishing bipolar and freehand percussion artifacts, and few experimental studies have been done at the site (Pei and Zhang 1985; Leng 1998). Thus we ask here two separate, but related questions: 1) are bipolar products easily distinguished from freehand percussion products at ZKD1? and 2) which method contributes more to the lithic industry at ZKD1? To investigate these questions, we formulated two simple hypotheses, which we tested via experimental replication and observation of archaeological materials.

Hypothesis 1: Bipolar products are easily distinguished from freehand percussion products. Several research experiments have demonstrated the differences between bipolar and freehand reduction products, and Pei and Zhang (1985) also gave some descriptions of bipolar reduction experiments at Zhoukoudian. However, Pei and Zhang's descriptions demonstrated only the reduction process of bipolar techniques and did not give more information about its products. Here, we use a modified version of Diez-Martín et al. (2011) to record the features of bipolar products and then to build an experimental framework for the recognition of bipolar products.

Hypothesis 2: The bipolar technique played more important role at ZKD1 than other flaking techniques. Numbers of usable flakes and lengths of their cutting edge were recorded to assess the productivity of different techniques in experimental study. A sample of artifacts from layers 4-5 was recorded to check the productivity of different reduction methods. Flake types of a retouched tool sample and their numbers were counted to evaluate the selection tendency of Homo erectus and then to evaluate the role of different techniques played at ZKD1. We also checked Pei and Zhang's data to evaluate the contributions of different reduction methods to the whole assemblage in layers 4-5. 


\section{Materials and methods}

Zhoukoudian Locality 1 was found in 1921 , and $300 \mathrm{~m}^{2}$ were excavated as part of field campaigns in 1928-1937, 1949-1966, and 1978-1982 (Zhang 2003). From 2009, an ongoing rescue excavation program started, and up to $20 \mathrm{~m}^{2}$ were exposed. The stratigraphic sequence, with a total thickness of $\sim 40 \mathrm{~m}$, consists of 17 layers, the upper eleven of which contain Paleolithic remains (Jia 1959). The age of the sequence varies due to different dating methods, from 770ka to 230ka (Grün et al. 1997; Shen et al. 2001, 2009; Chen and Zhou 2009).

The sources of quartz were reported very poorly and the author and colleagues have conducted a survey surrounding the Dragon Bone Hill in 2009 which located several vein quartz outcrops ( $\mathrm{Li}$ et al. 2011). Quartz fragments collected in the north metamorphic rock area of the site and one nodule collected near Tianyuan Cave, $6 \mathrm{~km}$ southwest of ZKD1, were used for experimental bipolar and freehand reductions. Quartz pebbles were exploited by the Zhoukoudian hominins, as shown by artifacts with pebble cortex, and some scholars have claimed that they were easily collected in the gravel layers and modern riverbed (Black et al. 1933; Du 2007). However, in our survey, only one quartz pebble was collected over two hours. Although the terraces of the Zhoukouhe River have been strongly disturbed, which might have changed the composition of the gravel layers, the proportion of quartz pebbles should generally have been low because very few artifacts were made from quartz pebbles, but more were manufactured from quartz nodules collected from the outcrops ( $\mathrm{Li}$ et al. 2011). The small nodules were left in their original form for replication and no pre-experimental modification occurred. Three larger ones were first flaked with a freehand method, and then some small chunks were selected for flaking with a bipolar method. In total, 18 quartz nodules and chunks were procured and their metric dimensions recorded (Table 1).

A large plastic sheet was placed on the ground, and upon that was a sandstone anvil on which 15 bipolar reductions were carried out by the author, while hard hammer percussion was conducted on three other quartz nodules using a freehand 
gesture (Fig. 1). The goal of each reduction was to produce as many usable flakes as possible from each nodule. A usable flake was defined as having two attributes: 1) a maximum dimension of at least 25mm (Gurtov and Eren 2014) and 2) an edge segment with an angle of no more than $75^{\circ}$ (Diez-Martín et al. 2011). Metrical, mechanical, and functional variables were recorded including 15 attributes following a modified version of Diez-Martín et al. (2011) (Table 2). From the three freehand reductions, 171 artifacts $(>10 \mathrm{~mm})$ were recorded, while only 14 usable flakes were produced. From the fifteen bipolar reductions, 255 artifacts $(>10 \mathrm{~mm})$ were recorded, and 21 usable flakes were produced.

Numerous stone artifacts were unearthed from the old ZKD excavations, but only 17,131 artifacts were studied in Pei and Zhang's work due to some loss during transportation of the archaeological materials (Table 3) (Pei and Zhang 1985; Zhang, 1985). Among the collections from layers 1 to 11, the assemblage from layers 4-5 (c. $300 \mathrm{ka}$ ) is the largest one, and also has more bipolar products. Considering that quartz artifacts are the majority (95.8\%) and also more commonly associated with the bipolar technique, we chose a sample of the quartz artifacts from layers 4-5 stored in the Institute of Vertebrate of Paleontology and Paleoanthropology (IVPP, Beijing), Chinese Academy of Sciences, as our main research material (Table 4). A total of 6651 artifacts were recorded by Pei and Zhang from layers 4-5, but their original classification for the artifacts, which were not described in detail, cannot be identified. The artifacts are currently stored in small bags labeled with different types following the classification by Prof. Qiu Zhonglang in IVPP, and 1 bag of cores, 10 bags of flakes and 5 bags of retouched tools were reclassified and recorded in this study with 610 artifacts in total. A sample of 535 quartz artifacts including 42 cores, 324 flakes, 97 chunks and chips, and 72 retouched tools were analyzed to assess the contribution of bipolar and freehand reduction methods to the ZKD1 lithic industry.

\section{Results}

3.1 An experimental referential framework for distinguishing bipolar reduction products 
Overall, bipolar reduction does produce assemblages different from those produced by freehand percussion. In the freehand and bipolar experimental reductions, the percentages of shatters (including chunks and chips) are both very high, $62.7 \%$ for bipolar and $83 \%$ for freehand reduction. The higher proportion of shatters in freehand reductions is mainly due to the frequent occurrence of fissures in vein quartz, and some of these easily fracture into shatters when applying freehand reduction. For example, E5 is a large quartz chunk, and only 1 flake was produced by freehand percussion with 1 core fragment and 79 shatters, while using four of its shatters 16 flakes with 2 core fragments and 29 shatters were produced by the bipolar method. The point of percussion and plain platforms are easier to find on the flakes produced freehand, and bulbs of percussion are usually absent both on bipolar and freehand flakes. The curvature of blanks is generally straight for bipolar flakes $(62 / 74=83.8 \%)$, while freehand flakes have more curved ones $(10 / 20=50 \%)$. The most diagnostic feature of bipolar products is the crushed areas on one or two ends of the bipolar flakes and cores resulting from contact with hammers and anvils (see Fig. 2), and these are very rare on freehand reduction flakes.

Bipolar reduction produced more usable flakes and also more cutting edges per unit mass than freehand reduction, but freehand reduction produced a higher percentage of usable flakes and more usable edges per flake. Overall, $39.04 \mathrm{~g}$ of quartz produced one usable flake by the bipolar method while the mean mass for producing one flake by freehand reduction is $173.68 \mathrm{~g}$. Overall, $10 \mathrm{~mm}$ of cutting edges produced by bipolar require $11.8 \mathrm{~g}$ of quartz, but $23.5 \mathrm{~g}$ when the freehand method was applied. In my experiments, 80 bipolar flakes and 20 freehand reduction flakes were recorded, and among those flakes 21 usable bipolar blanks (26.3\%) and 14 usable freehand reduction blanks (70\%) were identified. The mean usable edges per flake for bipolar reduction are $29.8 \mathrm{~mm}$ but $49.2 \mathrm{~mm}$ for freehand reduction ( $\mathrm{p}=0.02$, Sig. 2-tailed). The usable flake maximum dimension produced by freehand is not significantly larger than bipolar flakes $(\mathrm{p}=0.86$, Sig. 2-tailed) even though the original nodules for freehand are much larger. However, bipolar flake mass is significant smaller than freehand reduction flake mass ( $\mathrm{p}=0.046$, Sig. 2-tailed). 
3.2 Contributions to the lithic industry of layers 4-5 at ZKD1 by different reduction methods

Bipolar and freehand reduction products were distinguished following the descriptive characteristics listed above, and 177 bipolar flakes and 118 freehand reduction flakes were recorded in this study. Among those flakes, 74 bipolar usable blanks (41.8\%) and 87 usable freehand reduction blanks (73.7\%) were identified (Fig. 2). Although the usable flakes and cutting edges per unit mass cannot be evaluated here because the original mass of raw material prior to reduction is hard to determine, the functional variables per flake can be noted. Freehand reduction flakes provide more usable edges per flake than bipolar flakes. The mean cutting edges per flake are $36.2 \mathrm{~mm}$ for freehand and $26.7 \mathrm{~mm}$ for bipolar flakes $(\mathrm{p}<0.001$, Sig. 2-tailed). The usable flake maximum dimension produced by freehand is significantly larger than bipolar flakes ( $\mathrm{p}=0.001$, Sig. 2-tailed), and their means are $39.6 \mathrm{~mm}$ and $35.3 \mathrm{~mm}$ respectively. The mean mass of quartz bipolar flakes is $7.4 \mathrm{~g}$ but is $16.9 \mathrm{~g}$ for freehand reduction flakes, and the difference is significant (p<0.001, Sig. 2-tailed) (Fig. 3).

A total of 72 retouched quartz tools were recorded in this study, and their blanks are highly variable including pebbles $(\mathrm{N}=1)$, cores $(\mathrm{N}=1)$, freehand reduction flakes $(\mathrm{N}=17)$, bipolar flakes $(\mathrm{N}=8)$, flake fragments $(\mathrm{N}=21)$ and chunks $(\mathrm{N}=24)$. More freehand reduction flakes were selected as tool blanks than bipolar flakes in this sample. The maximum dimensions of blanks are not significantly different $(\mathrm{P}=0.835$, Sig. 2-tailed) thought the mean maximum dimension of bipolar blanks (mean=36.9 $\mathrm{mm}$ ) is slightly larger than that of freehand reduction blanks (mean=35.8 mm) (Fig. 3). The masses of different types of blanks are also not significantly different $(p=0.829$, Sig. 2-tailed).

Referring to the data in Pei and Zhang (1985), tool blanks in layers 4-5 include pebbles $(\mathrm{N}=18)$, cores $(\mathrm{N}=13)$, chunks $(\mathrm{N}=350)$, bipolar flakes $(\mathrm{N}=349)$, freehand reduction flakes $(\mathrm{N}=312)$, and flake fragments $(\mathrm{N}=326)$. The numbers of bipolar flakes and freehand reduction flakes are similar but were not the dominant blanks for making tools. Considering the uncertainty of defining bipolar flakes, the number of 
bipolar blanks might have been overestimated in the previous study.

\section{Discussion and conclusion}

Recognition of the bipolar technique usually relies on the diagnostic pieces like cores and flakes (Binford and Quimby 1963; Flenniken 1981; Barham 1987; Ahler 1989; Diez-Martín et al. 2011), although some have advocated a method focusing on assemblage-level debitage patterning (Kuijt et al. 1995). It is important to study the whole assemblage to define the flaking techniques, but the high percentage of non-diagnostic shatters of bipolar reduction can be of little help for identifying the presence of this flaking method at a given site (Barham 1987; Kuijt et al. 1995; Diez-Martín et al. 2011). More importantly, it is hard to determine the presence of bipolar technique purely by depending on the non-diagnostic shatters, if no bipolar cores and flakes are found. In the assemblages at ZKD1, pieces with crushing areas at one or two ends are much more diagnostic for differentiating bipolar products from products flaked by other methods, and this is consistent with experimental studies (Binford and Quimby 1963; Flenniken 1981; Barham 1987; Ahler 1989; Diez-Martín et al. 2011). However, the flaking methods of shatters are very hard to identify which makes the initial raw material mass reduced by different methods hard to determine in an archaeological assemblage. Consequently, some of the functional variables of different types of blanks are not easy to evaluate, such as the number of usable flakes per unit mass, and the length of cutting edges per unit mass. However, bipolar reduction requires much less raw material than freehand reduction for the same amount of usable flakes and cutting edges.

The bipolar method was thought to be the dominant flaking method at ZKD 1 in Pei and Zhang (1985), often cited in Paleolithic literature (e.g., Zhang 1985; Keates 2000; Wang 2005; Dennell 2009). However, the results observed in the sample from layers 4-5 at ZKD1 show that bipolar reduction does not produce more usable and superior flakes than freehand reduction, as has been demonstrated in other experiments (Diez-Martín et al. 2011; Eren et al. 2013; Gurtov and Eren 2014). Although it is hard to determine the number of usable flakes per unit mass of raw 
material, the percentage of usable blanks in the freehand reduction assemblage is much higher than that in bipolar reduction assemblage. In other words, the usable flake productivity of freehand reduction is much higher than bipolar reduction if raw material mass is not considered. The maximum dimension and length of cutting edge of freehand reduction flakes are both significantly larger than that of bipolar reduction. The blanks for retouched tools include variable artifact types and bipolar flakes are not the dominant ones in the sample of this study and also in the data published in Pei and Zhang's (1985) book. Overall, the number of bipolar products in the ZKD1 assemblages may be larger than that of freehand reduction artifacts; however, the bipolar method might not play a more important role at ZKD 1 than freehand reduction. The contribution of bipolar flaking method to the lithic industry of ZKD1 has been overestimated.

Bipolar reduction is highly associated with quartz material, and is also thought to have been an expedient strategy (Eren et al. 2013; Gurtov and Eren 2014). Referring to the close relations between bipolar reduction and quartz, two questions should be asked: 1) is bipolar reduction the only or best way to flake quartz?, and 2) do knappers intentionally choose the bipolar method to exploit quartz to deal with certain problems? At ZKD 1 freehand reduction played a more important role in producing blanks from quartz material, and obviously the bipolar method is not the only way to exploit quartz. The question then is, why were bipolar reductions chosen intentionally if freehand reduction could produce more usable flakes? One explanation is that bipolar reduction was not the first choice to produce blanks when the quartz was collected initially, but was an expedient strategy to supply cutting edges when offhand requirements on site arose. Quartz is liable to fragment when freehand reduction is applied, and the shatters are usually too small to be exploited again with a freehand method. When some expedient usage of cutting edge was required on site, bipolar reduction was an efficient way to produce several usable flakes from large shatters left by freehand reduction instead of collecting new raw material to make flakes with a freehand method. The other explanation is that some of the collected quartz nodules were small and only possible to flake with a bipolar method. Quartz is easy to collect 
and the maximum dimension of the nodules is usually larger than $5 \mathrm{~cm}$ at the outcrops nearby the site (Li et al. 2011). Although the quartz veins are not concentrated in one spot, there would been few time constrains in collecting them. For these reasons, there is a low possibility that the ZKD occupants collected numerous small quartz nodules at the beginning.

There are some unconformities between the data from the experiments and that from the archaeological sample, such as the maximum dimension of bipolar flakes and freehand reduction flakes that may be due to the small number of usable flakes in the experimental data. However, these data indicate that freehand reduction is likely to produce a higher percentage of usable flakes and also more cutting edges per flake than that by bipolar reduction. Therefore, it can be concluded that in layers 4-5 of ZKD 1, bipolar reduction was an expedient strategy that supplemented freehand reduction. Consequently, it should be treated as an adaptive characteristic of the ZKD 1 assemblages instead of an evolutionary one, and is also not an indicator of technological diffusion or cultural tradition. A study on the whole assemblage from ZKD 1 and comparisons among different layers should be done in future.

\section{Acknowledgements:}

I would like to thank Prof. Xing Gao and Prof. Robin Dennell to invite me to write this paper, and thank Prof. Dennell for valuable comments on the manuscript. I gratefully acknowledge Dr. Zhang Shunquan, Dr. Liu Decheng, Wei Yi from IVPP (Beijing), and Dr. Wangchunxue from Jilin University to do the raw material survey and collect the quartz nodules. I would like also to thank Ma Ning in IVPP for help in obtaining access to the ZKD collections. This work was supported by the CAS Strategic Priority Research Program (Grant XDA05130202) and the National Science Foundation for Fostering Talents in Basic Research of the National Natural Science Foundation of China (Grant J1210008).

\section{References}

Ahler, S.A., 1989. Experimental knapping with KRF and mid-continental cherts: 
overview and applications. In: Amick, D.S., Mauldin R.P. (Eds), Experiments in Lithic technology, Oxford: British Archaeological Reports International series $528,199-234$.

Barham, L.S., 1987. The bipolar technique in Southern Africa: a replication experiment. The South African Archaeological Bulletin 42, 45-50.

Binford, L.R., Quimby, G.I., 1963. Indian sites and chipped stone materials in the Northern Lake Michigan area. Fieldiana: Anthropology 36, 277-307.

Black, D., Teilhard de Chardin, P., Young, C.C., Pei, W.Z., 1933. Fossil man in China: The Choukoutien Cave deposits with a synopsis of our present knowledge of the Late Cenozoic in China. Geological Survey of China (Series A), Memoirs 11, $1-174$

Breuil, H., 1931. Le feu et l' industries et osseuse á Choukoutien. Bulletin of the Geological Society of China 11, 147-154 (in French).

Chen, C., 1998. Bipolar technique and pièce esquillés. Acta Anthropologica Sinica 17, 73-80 (in Chinese).

Chen, T.M., Zhou, L.P., 2009. Dating of the Peking Man Site: a comparison between existing chronology and the ${ }^{26} \mathrm{Al} /{ }^{10} \mathrm{Be}$ burial ages. Acta Anthropologica Sinica 28, 285-291 (in Chinese with English abstract).

Dennell, R., 2009. The Palaeolithic Settlement of Asia. New York: Cambridge University Press.

Diez-Martín, F., Yustos, P.S., Domínguez-Rodrigo, M., Prendergast, M.E., 2011. An experimental study of bipolar and freehand knapping of Naibor Soit quartz from Olduvai Gorge (Tanzania). American Antiquity 76, 690-708.

Diez-Martín, F., Sánchez, P., Dominguez-Rodrigo, M., Mabulla, A., Barba, R., 2009. Were Olduvai Hominins Making Butchering Tools or Battering Tools? Analysis of a Recently Excavated Lithic Assemblage from BK (Bed II, Olduvai Gorge, Tanzania). Journal of Anthropological Archaeology 28, 274-289.

Driscoll, K., 2011. Vein quartz in lithic traditions: an analysis based on experimental archaeology. Journal of Archaeological Science 38, 734-745.

Du, S.S., 2007. Paleolithic Culture at North part of North China. The Commercial 
Press, Beijing, pp. 169-247 (in Chinese).

Eren, M.I., Diez-Martin, F., Dominguez-Rodrigo, M., 2013. An empirical test of the relative frequency of bipolar reduction in Beds VI, V, and III at Mumba Rockshelter, Tanzania: implications for the East African Middle to Late Stone Age transition. Journal of Archaeological Science 40, 248-256.

Flenniken, J.J., 1981. Replicative systems analysis: a model applied to the vein quartz artifacts from the Hoko River site. Washington State University, Laboratory of Anthropology, Report of Investigations No. 59, Pullman.

Grün, R., Huang, P.H., Wu, X.Z., Stringer, C.B., Thorne, A.G., McCulloch, M., 1997. ESR analysis of teeth from the paleoanthropological site of Zhoukoudian, China. Journal of Human Evolution 32, 83-97.

Gurtov, A.N. Eren, M.I., 2014. Lower Paleolithic bipolar reduction and hominin selection of quartz at Olduvai Gorge, Tanzania: What's the connection? Quaternary International 322-323, 285-291.

Hiscock, P., 2015. Making it small in the Palaeolithic: bipolar stone-working, miniature artefacts and models of core recycling. World Archaeology 47, 158-169.

Jia, L.P., 1959. An excavation report of the Choukoutien cave in 1958. Palaeovertebrata et Paleoanthropologia 1, 21-26 (in Chinese).

Keates, S.G., 2000. Early and Middle Pleistocene Hominid Behaviour in Northern China. Oxford: BAR International Series 863.

Kuijt, I., Prentiss, W.C., Pokotylo, D.L., 1995. Bipolar reduction: an experimental study of debitage variability. Lithic Technology 20, 116-127.

Leakey, M.D., 1971. Olduvai Gorge, vol. 3. Excavations in Bed I and II, 1960-63. Cambridge University Press, Cambridge.

Leng, J., 1998. Early Palaeolithic quartz industries in China. In: Petraglia, M., Korisettar, R., (Eds). Early Human Behavior in Global Context: The Rise and Diversity of the Lower Palaeolithic Record. London: Routledge, pp. 418-436.

Li, F., Wang, C.X., Liu, D.C., Zhang, X.L., Zhang, S.Q., Gao, X., 2011. Vein quartz procurement at layers 4-5 of the Zhoukoudian locality 1. Quaternary Sciences 31, 
900-908 (in Chinese with English abstract).

LeBlanc, R., 1992. Wedges, Pieces Esquillées, Bipolar Cores, and Other Things: an alternative to Shott's View of Bipolar Industries. North American Archaeologist $13,1-14$.

Lowe, C.V.R., 1946. The costal Smithfield and bipolar technique. South African Journal of Science 42, 240-246.

Pei, W.C., 1931. Preliminary note of the discovery of quartz and other stone artifacts in the Lower Pleistocene hominid bearing-sediments of the Choukoutien cave deposit. Bulletin of the Geological Society of China 11, 203-250.

Pei, W.C., Zhang, S.S., 1985. A Study on the Lithic Artifacts of Sinanthropus. Science Press, Beijing (in Chinese with English abstract).

Shen, G.J., Gao, X., Gao, B., Granger, D.E., 2009. Age of Zhoukoudian Homo erectus determined with ${ }^{26} \mathrm{Al} /{ }^{10} \mathrm{Be}$ burial dating. Nature 458, 198-200.

Shen, G.J., Ku, T.L., Cheng, H., Edwards, R.L., Yuan, Z.X., Wang, Q., 2001. High-precision U-series dating of Locality 1 at Zhoukoudian, China. Journal of Human Evolution 41, 679-688.

Shott, M.J., 1989. Bipolar industries: ethnographic evidence and archaeological implications. North American Archaeologist 10, 1-24.

Shott, M.J., 1999. On bipolar reduction and splintered pieces. North American Archaeologist 20, 217-238.

Wang, Y.P., 2005. Roots of Pleistocene Hominids and Cultures in China. Beijing: Science Press (in Chinese).

Weiner, S., Xu, Q.Q., Goldberg, P., Liu, J.Y., Bar-Yosef, O., 1998. Evidence for the use of fire at Zhoukoudian, China. Science 281, 251-53.

Wu, X.J., Pan, L., 2011. Identification of Zhoukoudian Homo erectus brain asymmetry using 3D laser scanning. Chinese Science Bulletin 56, 2215-2220.

Zhang, S. S., 1983. Bipolar flakes as a bond of ancient culture in China. Fossils 4, 6-8 (in Chinese).

Zhang, S.S., 1998. The bipolar technique in the Paleolithic industry in China. In: Department of Archaeology, Peking University (Ed), Proceedings of the 
International Conference on "Chinese Archaeology Enters the Twenty-first Century”. Beijing: Science Press, pp. 51-74 (in Chinese with English abstract).

Zhang, S. S., 1995. The early Paleolithic of China, In: Wu, R.K., Olsen, J.W. (Eds.) Paleoanthropology and Paleolithic archaeology in the People's Republic of China. Orlando (FL): Academic Press, pp. 147-186.

Zhang, S.S., 2003. The Peking Man Site Annals. Beijing: Beijing Press (in Chinese).

Zhang, Y., Guo, Z.T., Deng, C.L., Zhang, S.Q., Wu, H.B., Zhang, C.X., Ge, J.Y., Zhao, D.A., Li, Q., Song, Y., Zhu, R.X., 2014. The use of fire at Zhoukoudian: evidence from magnetic susceptibility and color measurements. Chinese Science Bulletin 59, 1013-1020. 
Fig.1. Examples of quartz nodules and fragments, and percussion tools used in the experiments. Nos. 1,2,4 were flaked with a freehand method; 3,5 were flaked with a bipolar method; 6, hammerstone for bipolar reduction; 7, hammerstone for freehand reduction; 8 , anvil for bipolar reduction

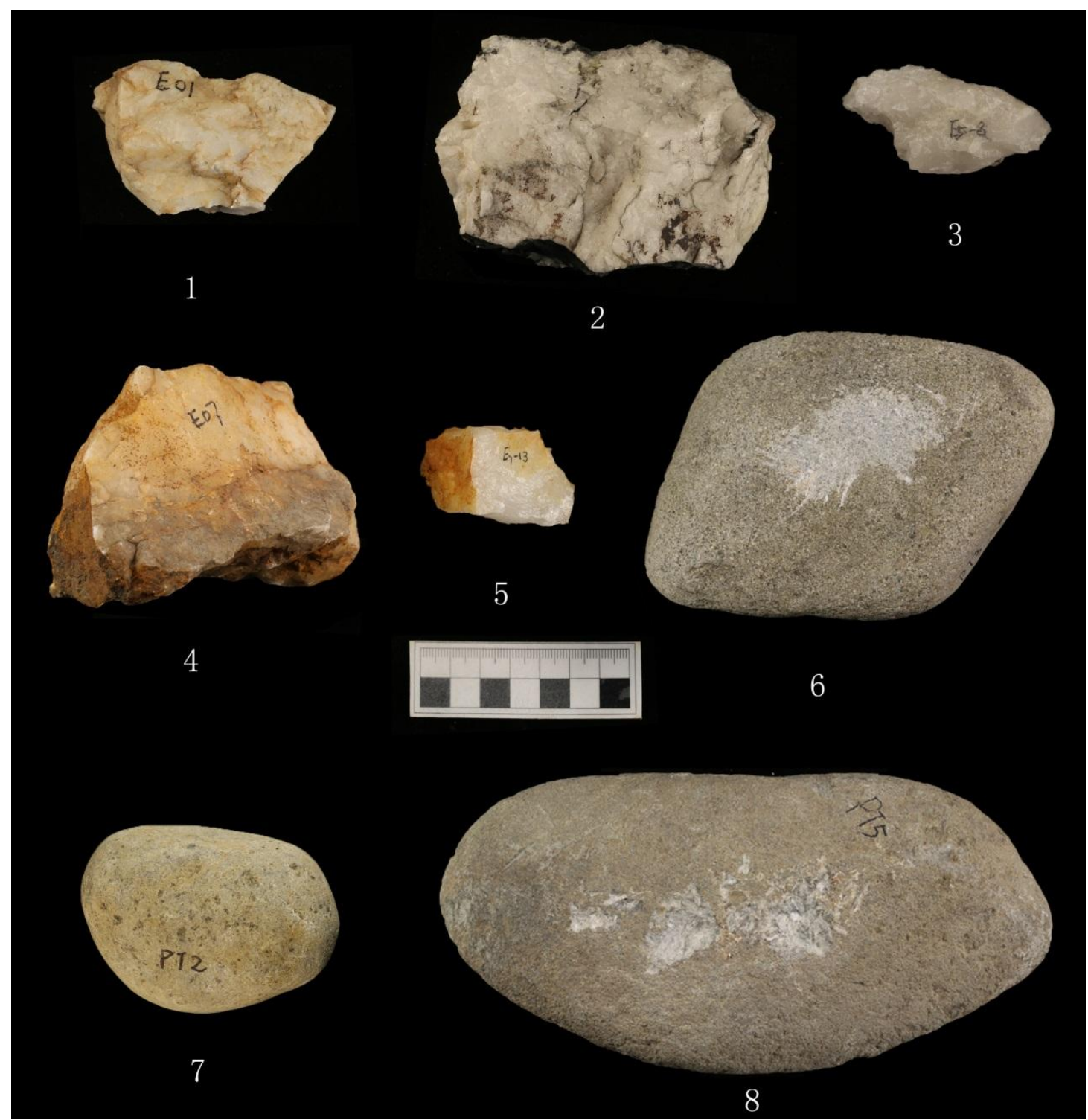


Fig. 2. Examples of flakes produced by bipolar and freehand reductions. 1-3, bipolar flakes from the experiment; 4-6, freehand reduction flakes from the experiment; 7-9, bipolar flakes from layers 4-5 at ZKD1; 10-12, freehand reduction flakes from layers 4-5 at ZKD1.

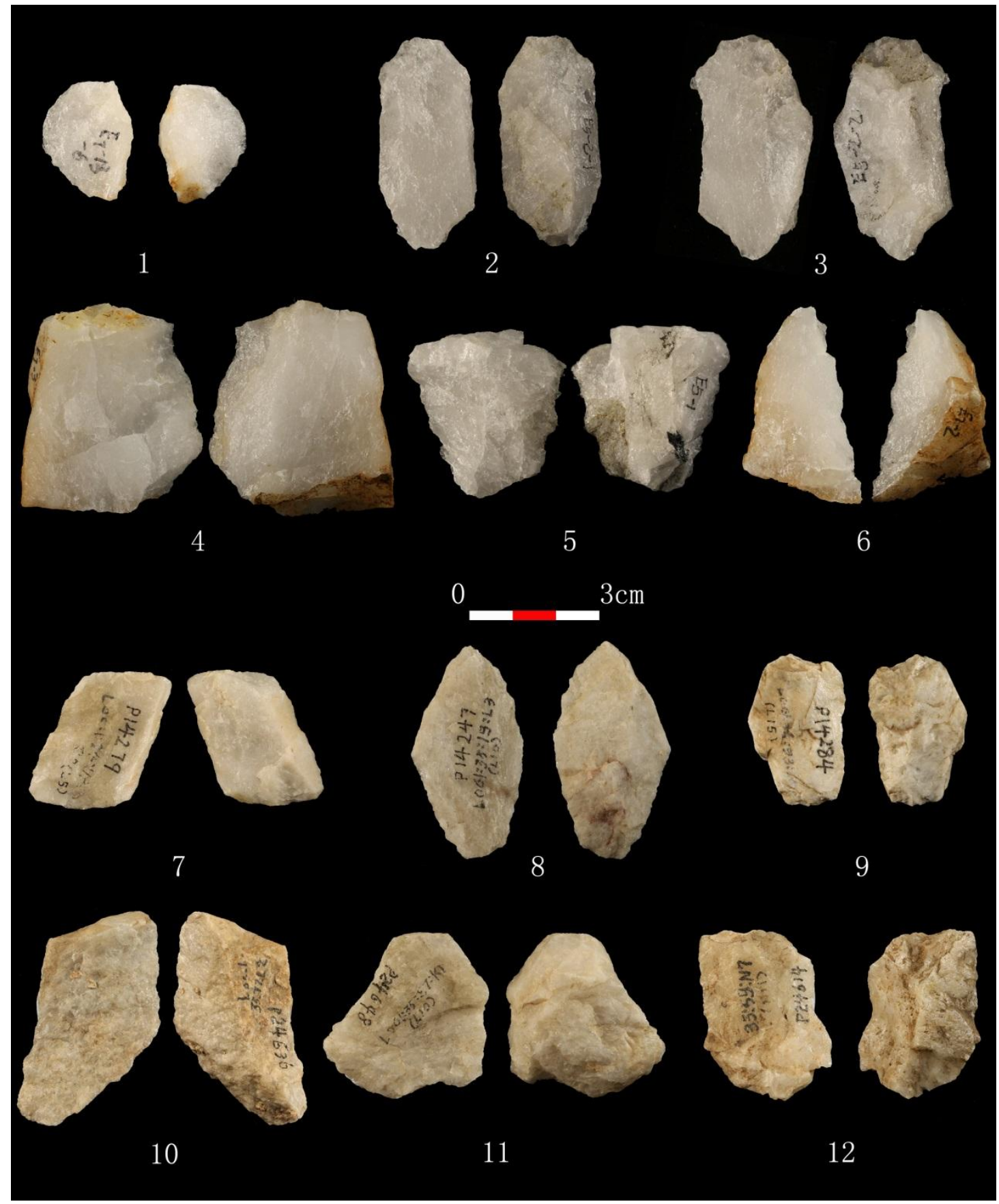


Fig. 3. Comparisons of the freehand reduction and bipolar flake samples from layers 4-5 at ZKD1.

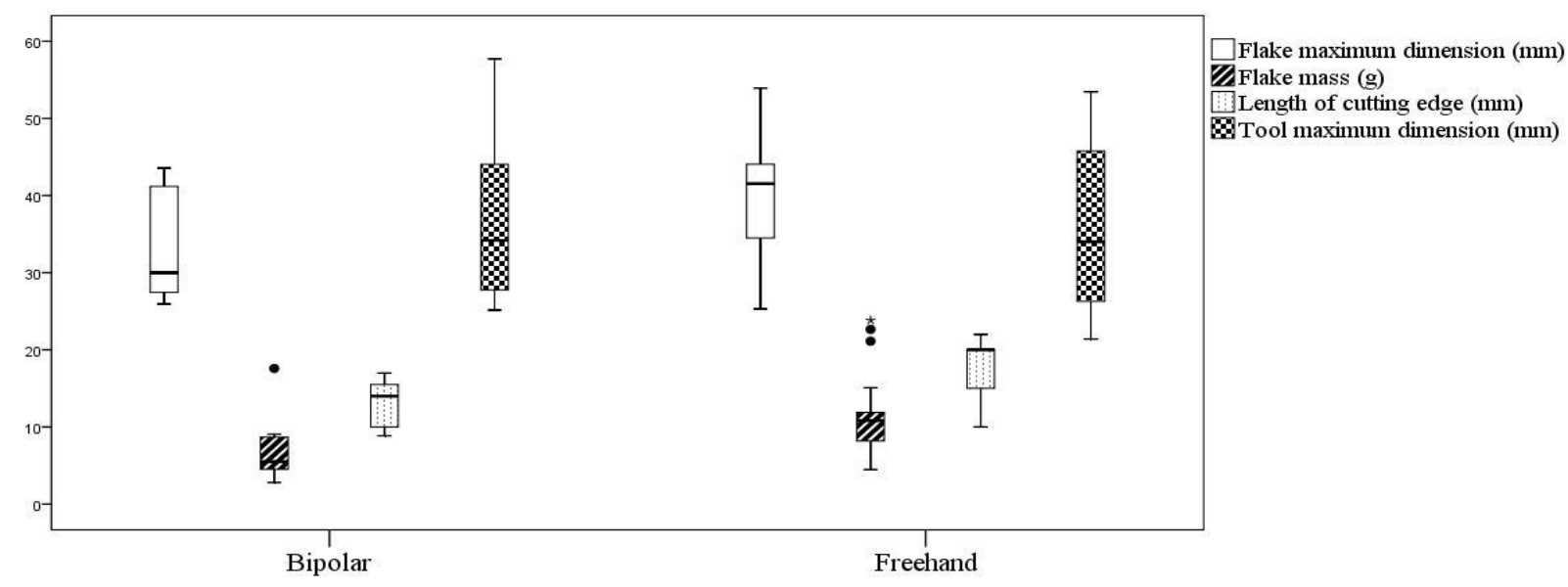


Table 1 Metric data on the experimental nodules and chunks before reduction

\begin{tabular}{|c|c|c|c|c|c|c|c|}
\hline Number & $\begin{array}{l}\text { Mass } \\
(\mathrm{g})\end{array}$ & $\begin{array}{c}\text { Length } \\
(\mathrm{mm})\end{array}$ & $\begin{array}{l}\text { Width } \\
\text { (mm) }\end{array}$ & $\begin{array}{c}\text { Thickness } \\
\text { (mm) }\end{array}$ & $\begin{array}{c}\text { Reduction } \\
\text { method }\end{array}$ & $\begin{array}{c}\text { Number of } \\
\text { usable flakes }\end{array}$ & $\begin{array}{l}\text { Length of cutting edge } \\
(\mathbf{m m})^{\mathrm{a}}\end{array}$ \\
\hline E1 & 186.49 & 79.63 & 51.14 & 45.05 & Freehand & 2 & 38 \\
\hline E2 & 148.11 & 73.86 & 49.18 & 73.86 & Bipolar & 0 & 0 \\
\hline E3 & 46.77 & 55.79 & 34.36 & 55.79 & Bipolar & 1 & 15 \\
\hline $\mathrm{E} 4$ & 113.76 & 82.27 & 51.83 & 82.27 & Bipolar & 3 & 88 \\
\hline E5 & 1707.2 & 245 & 98 & 66.53 & Freehand & 1 & 145 \\
\hline E7 & 537.86 & 101.89 & 65.04 & 64.27 & Freehand & 11 & 850 \\
\hline E1-5 & 50.24 & 42.21 & 35.24 & 30.9 & Bipolar & 1 & 18 \\
\hline E1-6 & 40.35 & 46 & 35.6 & 27.17 & Bipolar & 2 & 48 \\
\hline E1-8 & 14.75 & 29.49 & 26.16 & 19.09 & Bipolar & 0 & 0 \\
\hline E5-2 & 26.67 & 56.11 & 29.82 & 18.56 & Bipolar & 2 & 94 \\
\hline E5-3 & 55.32 & 73.92 & 42.95 & 17.91 & Bipolar & 0 & 18 \\
\hline E5-4 & 29.8 & 58.06 & 33.74 & 19.99 & Bipolar & 1 & 22 \\
\hline E5-6 & 66.31 & 62.32 & 48.12 & 26.66 & Bipolar & 1 & 24 \\
\hline E7-13 & 71.04 & 59.31 & 45.89 & 35.38 & Bipolar & 4 & 150 \\
\hline E7-14 & 22.81 & 51.93 & 21.87 & 17.21 & Bipolar & 0 & 0 \\
\hline E7-15 & 54.58 & 44.82 & 44.19 & 23.34 & Bipolar & 1 & 14 \\
\hline E7-16 & 36.32 & 41.68 & 29.92 & 28.83 & Bipolar & 3 & 110 \\
\hline E7-17 & 43.02 & 45.14 & 42.27 & 16.64 & Bipolar & 2 & 96 \\
\hline
\end{tabular}

\footnotetext{
${ }^{a}$ some shatters with usable edges were recorded when length of cutting edges were counted.
} 
Table 2 Attributes selected for this study

\begin{tabular}{|c|c|}
\hline Point of Percussion & 0. Absent; 1. Diffuse; 2. Present \\
\hline Bulb of force & 0. Absent; 1. Diffuse; 2. Present \\
\hline Platform types & 0. Absent; 1. Cortical; 2. Plain; 3. Punctiform; 4. Linear crushing \\
\hline Interior platform angle & Measured as degree \\
\hline Exterior platform angle & Measured as degree \\
\hline Curvature of blanks & 1. Straight; 2. Curved; 3. Twisted \\
\hline Lateral edges of blanks & 1. Parallel and Subparallel; 2. Convergent; 3. Expanding; 4. Irregular \\
\hline Termination & 1. Feather; 2. Step; 3. Hinge; 4. Overshot; 5. Crushing \\
\hline Crushing and splinting & 1. No Crushing; 2. Crushing on one surface; 3 . Crushing on two surfaces \\
\hline Length, Width, and Thickness & Measured as centimeters \\
\hline Weight & Measured as grams \\
\hline Number of cutting edges & Counting left-sided, right-sided, and distal segments \\
\hline Length of cutting edges & Measured as centimeters \\
\hline Cutting edge angle & Measured as degree \\
\hline
\end{tabular}


Table 3 Classifications and counts of stone artifacts reported by Pei and Zhang (1985)

\begin{tabular}{|c|c|c|c|c|c|c|c|c|c|c|c|c|c|c|c|c|c|}
\hline \multirow[b]{2}{*}{ Layer } & \multicolumn{3}{|c|}{ Core } & \multicolumn{3}{|c|}{ Flake } & \multicolumn{2}{|c|}{ Hammerstone } & \multirow{2}{*}{ Anvil } & \multirow{2}{*}{ Sidescraper } & \multirow{2}{*}{ Pointed tool } & \multirow{2}{*}{ Awl } & \multirow{2}{*}{ Burin-like tool } & \multirow{2}{*}{$\begin{array}{l}\text { Chopper and } \\
\text { Chopping tool }\end{array}$} & \multirow{2}{*}{ Spheroid } & \multirow{2}{*}{ Shatter } & \multirow{2}{*}{ Total } \\
\hline & BP & FH & AV & BP & FH & AV & BP & FH & & & & & & & & & \\
\hline L.3 & 7 & 4 & & 153 & 22 & & 6 & 4 & 10 & 207 & 55 & 4 & 21 & 4 & & 88 & 585 \\
\hline $1-3$ & 44 & 12 & & 556 & 191 & 8 & 5 & 3 & 2 & 349 & 55 & 13 & 17 & 22 & 2 & 2205 & 3484 \\
\hline $4-5$ & 168 & 51 & 1 & 2313 & 638 & & 4 & 5 & 6 & 1067 & 199 & 21 & 48 & 32 & 1 & 2097 & 6651 \\
\hline 6 & 18 & 8 & & 179 & 60 & & 1 & & & 139 & 17 & & 6 & 5 & & 612 & 1045 \\
\hline 7 & & & & 22 & 11 & & & & & 6 & & & & 1 & & 119 & 159 \\
\hline QII & 6 & 19 & & 127 & 85 & & & 2 & & 88 & 17 & & 2 & 13 & 1 & 884 & 1244 \\
\hline 8-9 & 5 & 41 & 6 & 108 & 117 & 21 & & 25 & & 86 & 8 & & 2 & 63 & 4 & 850 & 1336 \\
\hline 10 & & 17 & & 35 & 36 & 5 & & & 1 & 61 & 7 & & & 13 & & 268 & 443 \\
\hline 11 & & 12 & 1 & 3 & & 2 & 1 & 1 & & 8 & & & & 2 & & 1 & 31 \\
\hline $\begin{array}{c}\text { Uncertain } \\
\text { layers }\end{array}$ & 16 & 9 & & 394 & 71 & 3 & & 4 & & 217 & 48 & 9 & 17 & 5 & & 1360 & 2153 \\
\hline Total & 264 & 173 & 8 & 3890 & 1231 & 39 & 17 & 44 & 19 & 2228 & 406 & 47 & 113 & 160 & 12 & 8484 & 17131 \\
\hline
\end{tabular}

Reference: BP, Bipolar; FH, Freehand; AV, Block-on-block

Table 4 Numbers and proportions of artifact raw material types in layers 4-5 reported by Pei and Zhang (1985)

\begin{tabular}{|c|c|c|c|c|c|c|c|}
\hline Raw Material & vein quartz & crystal & chert & sandstone & quartzite & lamprophyre & other 16 types \\
\hline Number & 5983 & 389 & 174 & 42 & 13 & 11 & 39 \\
\hline Proportion & $89.96 \%$ & $5.85 \%$ & $2.62 \%$ & $0.63 \%$ & $0.19 \%$ & $0.16 \%$ & $0.59 \%$ \\
\hline
\end{tabular}

